\title{
Do gender-dyads have different communication patterns? A comparative study in Western-European general practices
}

\author{
Atie van den Brink-Muinen ${ }^{\mathrm{a}, *}$, Sandra van Dulmen ${ }^{\mathrm{a}}$, \\ Verena Messerli-Rohrbach ${ }^{\mathrm{b}, *}$, Jozien Bensing ${ }^{\mathrm{c}}$ \\ ${ }^{a}$ NIVEL, Netherlands Institute of Primary Health, P.O. Box 1568, 3500 BN, Utrecht, The Netherlands \\ ${ }^{\mathrm{b}}$ Arbeitsgemeinschaft Arzt-Patienten Kommunikation, Basel, Switzerland \\ ${ }^{\mathrm{c}}$ NIVEL/Utrecht University, Utrecht, The Netherlands
}

\begin{abstract}
From the viewpoint of quality of care, doctor-patient communication has become more and more important. Gender is an important factor in communication. Besides, cultural norms and values are likely to influence doctor-patient communication as well. This study examined (1) whether or not communication patterns of gender-dyads in general practice consultations differ across and between Western-European countries, and (2) if so, whether these differences continue to exist when controlling for patient, GP and consultation characteristics. Doctorpatient communication was assessed in six Western-European countries by coding video taped consultations of 190 GPs and 2812 patients. Cluster analysis revealed three communication patterns: a biomedical, a biopsychosocial and a psychosocial pattern. Across countries, communication patterns of the female/female dyad differed from that of the other gender-dyads. Differences in communication patterns between countries could especially be explained by differences in consultations of male doctors, irrespective of the patients' gender. It is important to take into consideration differences between gender-dyads and between countries when studying gender effects on communication across countries or when comparing studies performed in different countries.
\end{abstract}

(C) 2002 Elsevier Science Ireland Ltd. All rights reserved.

Keywords: Doctor-patient communication; Gender differences; Communication patterns; General practice; International comparison

\section{Introduction}

With the continuous feminization of medical care (more than $50 \%$ female students in medicine and still more female GPs in several Western-European countries) the differences between men and women as general practitioners and their respective behaviour towards male and female patients are of increasing interest. Especially the number of consultations of female doctors with male patients will increase, but also female/female visits will be more common in the future. This shift may have consequences for the quality of care, because congruence or discongruence between doctor and patient gender may influence their communication.

Hypothesising differences between the four gender-dyads in doctor-patient communication (M/M, M/F, F/M, F/F, doctor and patient gender, respectively) is legitimised by the literature showing differences in communication between same- and cross-genders although, more similarities than

\footnotetext{
* Corresponding author. Tel.: +31-30-272-9639; fax: +31-30-272-9729 E-mail address: a.vandenbrink@nivel.nl (A.v.d. Brink-Muinen).

* Deceased 18 April 2001.
}

differences have been reported [1-6]. Moreover, most studies focused on gender differences between one group of the actors, i.e. doctors or patients, whereas the focus was seldom on all four combinations of doctor and patient gender (i.e. genderdyads). Insight into the communication pattern of these gender-dyads can be applied in training and teaching curricula.

Until now, nearly all studies have been performed within one country instead of across or between countries. Cultural differences between countries may influence doctor-patient communication as well as gender, by differences in norms, values, beliefs and attitudes with regard to health and healthcare. In order to investigate if and to what extent gender differences in communication can be generalised across nationalities, data from several countries are required. The Eurocommunication Study, a comparative study in six Western-European countries on doctor-patient communication in general practices, gives the opportunity to study differences between gender-dyads across and between countries.

\subsection{Literature on gender differences}

It has been widely shown that female and male doctors differ in their communication with patients. Female doctors 
show more affective behaviour, such as empathy, partnership building, emotional support and reassurances [1-6]. They also have been found to encourage patients' input through the use of concern and partnership statements [7]. Male doctors are likely to give more interpretations and paraphrases [8,9]. Contrary to these studies, Hall et al. [2] found no differences between female and male doctors in social conversation and emotional support.

Concerning instrumental behaviour, information appeared to be given more by female than male doctors, and female GPs are better at (therapeutic) listening and counselling [1-6]. Male doctors are likely to give more instructions, advisements and suggestions for patient behaviour, and they appear to be more verbally dominant and imposing during the visit $[8,9]$. However, some studies do not reveal differences in the overall amounts of words spoken $[10,11]$.

Female physicians are likely to have practice styles that are sensitive to the patient's psychosocial problems [12], and therefore, they may be better at the detection of the patient's feelings, including undisclosed agendas and conflict. They are also likely to give more psychosocial information to their patients than male doctors [4-6].

The non-verbal behaviour also differs between doctor's genders; female doctors are likely to gaze more in the direction of the patient, to use more back-channel (or listeners') responses, and to smile and nod more often [13]. Female doctors may also offer more options [10,14], and have more time to negotiate treatment possibilities, both with male and female patients [2]. This may be possible by the extra consultation time female doctors have due to longer consultations [15].

On the patients' side, female patients have been found to express more emotions [16], to like emotionally supportive talk more than men, and to give more partnership statements $[2,3]$. They are likely to give more responses to questions and to receive more explanations $[9,17]$, but fewer questions from the doctor [11]. Women appear to talk easier to a samegender doctor, and to give more information, especially about psychosocial issues [15]. Male patients are likely to present more facts [16], to get more attention from the doctor [9] and to be better liked than female patients [18].

Explanations given for differences between same- and cross-gender communication mainly concern two conflicting paradigms: gender socialisation and status (in)congruency [19]. On the one hand, women are likely to be socialised to accept a less directed, interactive communication pattern than men, when educated in communication skills. Men, on the other hand, appear to medically socialise easier than women, to be assertive and to dominate the flow and the topics of doctor-patient interaction. Power differences between opposite-gender-dyads may affect the status relationship between doctor and patient and lead to greater status congruency and equality between same-gender-dyads [20]. So, gender socialisation and status (in)congruency might be manifest in the relation-oriented approach of women and the task oriented approach of men.
Differences in communication between cross-gender and same-gender-dyads have been studied less often than differences between male and female doctors and patients, respectively. It has been shown that in the female/female consultation the doctor gives more positive statements and gazes more at the patient. The atmosphere between female doctor and female patient is likely to be friendlier than between a female doctor and a male patient [16,17]. Female patients appear to find it easier to disclose information about them when the doctor is a woman [16], and they are likely to discuss psychosocial problems more often. Because female doctors may be more inclined to seek for psychosocial problems with women, there is probably a double effect. This assumption agrees with the higher amount of psychosocial problems diagnosed with female patients [21]. In the female/female dyad the contribution of doctor and patient is likely to be almost equal [2].

Male and female patients are found to like giving psychosocial information to female doctors but less to males, and in general male patients talk to female doctors as much as female patients do [3]. Female doctors are found to show more interest in male than female patients [2].

Studies on communication patterns have mainly been focused on an analysis of communication by individual categories, instead of a broader typology of communication patterns. Roter found in her study [22] that patient gender appears to be unrelated to communication patterns, but that male doctors use more often a biomedical pattern, where female doctors are more likely to use a biopsychosocial, psychosocial or consumerist pattern.

Based on the literature above, the following differences in communication between the gender-dyads are expected:

- In the male/male dyad little affective talk and more instrumental talk, and more biomedical than psychosocial talk.

- In the male/female and female/male dyad an average amount of affective and instrumental talk, and more balance between biomedical and psychosocial talk.

- In the female/female dyad more affective and less instrumental talk, and more psychosocial than biomedical talk.

Presumably, the issues of gender socialisation and status incongruency may generalise across Western-European countries and cultures and may, therefore, have no influence on communication differences between countries. However, cultural differences, based on different cultural norms and values prevailing in a country, may influence doctor-patient communication.

\subsection{Literature on cultural differences}

Effective communication between doctors and patients is crucial for the quality of healthcare [23]. One of the prerequisites for effective (intercultural) communication is that doctors and patients agree on the patients' health 
problem and understand, acknowledge and respect each other's explanatory models for health and illness. Discrepant models may influence the way problems are presented and the outcomes of the consultation, such as satisfaction and compliance [24]. Scarce research on the field of cultural differences confirms that mutual understanding is more often worse between cross- than same-cultural patients $[25,26]$. Misunderstanding may result in an incorrect diagnosis by the doctor and non-compliance by the patient [27]. So, in examining doctor-patient communication, it is important to consider cultural differences, expressed in the patient's and doctor's beliefs about health and illness [28].

\subsection{Research questions}

This study aims at investigating differences between gender-dyads across and between six Western-European countries, and explaining these differences when taking into account patient, GP and consultation characteristics. This study examined (1) whether or not gender-dyads in communication patterns in general practice consultations differ across and between Western-European countries, and (2) if so, whether these differences continue to exist when controlling for patient, GP and consultation characteristics.

\section{Methods}

\subsection{Data collection}

Data were derived from the Eurocommunication Study (1996-1999) [29,30]. In this study, doctor-patient communication in general practice was compared between six Western-European countries: The Netherlands, United Kingdom, Spain, Belgium, Germany and Switzerland. National coordinators from universities and research institutes were responsible for implementing the study and collecting the data. The coordination, analysis and reporting were carried out by the NIVEL (The Netherlands Institute for Health Services Research).

\subsection{Study design}

The study design was cross-sectional. The numbers of GPs taking part were 27 from the United Kingdom, 27 from Spain and 31 from The Netherlands. In Belgium 20 Flemish (Flemish-speaking) GPs and 11 Walloon (Frenchspeaking) GPs participated, in Switzerland 20 Germanspeaking GPs and 11 French-speaking GPs participated, and in Germany 14 GPs from the Eastern part and 29 from the Western part of Germany participated. In each country 15 patients per GP were included in the observation study. In total 190 GPs (127 male and 63 female) took part in the study (Table 1).
Table 1

Number and percent of GPs by GPs' gender and country

\begin{tabular}{|c|c|c|c|c|c|}
\hline & \multicolumn{2}{|c|}{ Male GPs } & \multicolumn{2}{|c|}{ Female GPs } & \multirow[t]{2}{*}{ Total $N$} \\
\hline & $N$ & Percentage & $N$ & Percentage & \\
\hline The Netherlands & 15 & 48.4 & 16 & 51.6 & 31 \\
\hline UK & 23 & 85.2 & 4 & 14.8 & 27 \\
\hline Spain & 12 & 44.4 & 15 & 55.6 & 27 \\
\hline Belgium & 23 & 74.2 & 8 & 25.8 & 31 \\
\hline Germany & 32 & 74.4 & 11 & 25.6 & 43 \\
\hline Switzerland & 22 & 71.0 & 9 & 29.0 & 31 \\
\hline Total & 127 & & 63 & & 190 \\
\hline
\end{tabular}

\subsection{Sampling method}

The sampling method differed per country due to the GPs' willingness to participate or its practicability. The GPs were recruited by means of a random national sample (The Netherlands, Flemish-speaking Belgium), existing GP research networks (United Kingdom, Germany), quality circles (Switzerland, French-speaking Belgium), or health centres (Spain). In Germany there was also a call in specialist publications and the 'snowball' method was used. Language background was taken into account in Belgium (Flemish-French language) and Switzerland (German and French language), and in Germany the old divide (Western and Eastern Germany) was accounted for. The aim was to include equal numbers of male and female GPs, but this was only possible in Spain and The Netherlands, because female GPs appeared to be less willing to participate. Comparison of the GP sample with that of another European study [31] revealed only some other differences, such as urbanisation and vocational training [29,30].

Patients consulting the GP on the day(s) of data collection were approached at random in the practice. The exception was Switzerland, where the patients were informed about the video recordings when they made an appointment with the GP by phone. All patients were asked for informed consent before their consultation. The overall response rate was $79 \%$. In total 2812 patients $(59.5 \%$ women) participated (Table 2). Non-response analysis showed hardly any bias resulting from patients' refusal. There were only slight differences in health problems presented and somewhat more women than men refused to participate $[29,30]$.

\subsection{Measurement instruments}

Socio-demographic data and the practice characteristics of the GPs were collected by a questionnaire. Information about the patients was recorded by the GP on a registration form; this included such items as acquaintance with the patient and diagnoses that were coded following the International Classification for Primary Care (ICPC) [32]. 
Table 2

Gender-dyads (GP/patient) by country ( $N$ and percentage)

\begin{tabular}{|c|c|c|c|c|c|c|c|c|c|}
\hline & \multicolumn{2}{|c|}{$\mathrm{M} / \mathrm{M}$} & \multicolumn{2}{|l|}{$\mathrm{M} / \mathrm{F}$} & \multicolumn{2}{|l|}{$\mathrm{F} / \mathrm{M}$} & \multicolumn{2}{|l|}{$\mathrm{F} / \mathrm{F}$} & \multirow[t]{2}{*}{ Total $\Lambda$} \\
\hline & $N$ & Percentage & $N$ & Percentage & $N$ & Percentage & $N$ & Percentage & \\
\hline The Netherlands & 93 & 21.1 & 128 & 29.1 & 73 & 16.6 & 146 & 33.2 & 440 \\
\hline United Kingdom & 144 & 40.3 & 153 & 42.9 & 11 & 3.1 & 49 & 13.7 & 357 \\
\hline Spain & 67 & 15.4 & 125 & 28.7 & 70 & 16.1 & 174 & 39.9 & 436 \\
\hline Belgium & 175 & 37.7 & 176 & 37.9 & 30 & 6.5 & 83 & 17.9 & 464 \\
\hline Germany & 229 & 34.1 & 278 & 41.4 & 59 & 8.8 & 105 & 15.6 & 671 \\
\hline Switzerland & 148 & 33.3 & 164 & 36.9 & 39 & 8.8 & 93 & 20.9 & 444 \\
\hline Total & 856 & 30.5 & 1024 & 36.4 & 282 & 10.0 & 650 & 23.1 & 2812 \\
\hline
\end{tabular}

\subsection{Video observations}

Data about the doctor-patient communication were derived from videotapes of the consultations. Verbal affective and instrumental behaviour of GPs and patients, respectively, as well as GPs' non-verbal behaviour (patient-directed eye gaze) was measured by means of the Roter Interaction Analysis System (RIAS) [33]. This observation system measures biomedical and psychosocial aspects of doctor-patient communication. The system distinguishes both instrumental (task focused) and affective (socio-emotional) verbal behaviour in doctors and patients, reflecting the cure-care distinction. The unit of analysis is the utterance, or the smallest meaningful string of words. Utterances were assigned to mutually exclusive categories. Communication categories of GPs and patients were expressed as percentages of the total of utterances of GPs and patients, respectively. The following categories were used:

\subsubsection{Affective behaviour}

- Social talk: personal remarks (non-medical, about holiday or weather), laughs, jokes, approvals, and compliments.

- Agreement: signs of agreement (including back-channel responses) or understanding what was said.

- Rapport building: showing empathy, legitimisation, support, concern, worry, asking or giving reassurance, encouragement, and optimism.

- Facilitation: paraphrases, checks for understanding, asking for clarification, opinion, or repetition.

\subsubsection{Instrumental behaviour}

- Procedural statements (only GP): giving direction or instruction, transitions.

- Biomedical talk: asking questions, giving information and (only GP) counselling about medical and therapeutic issues.

- Psychosocial talk: asking questions, giving information and (only GP) counselling about issues of lifestyle, social context, psychosocial aspects, and feelings.

\subsubsection{Non-verbal behaviour}

- GP's patient-directed gaze: eye contact related to the time possible to look at the patient.

\subsubsection{Consultation characteristics}

- Length of consultation, in minutes.

- GP's speaking time: GP's conversational contribution proportional to the total count of utterances of GPs and patients together.

- Length of physical examination: related to the consultation length.

\subsubsection{Control variables used in the two-level multivariate analysis:}

- GP's and patient's age.

- Patient's educational level (low, middle, high).

- Suffering from emotional feelings and health status from the patient's perspective (COOP/WONCA charts, which have been validated for cross-cultural use [34]).

- GP's psychosocial diagnosis: chapters $\mathrm{P}$ and $\mathrm{Z}$ as coded in ICPC [32].

- GP's assessment of psychosocial background of the patients' problems $(1=$ pure somatic, $5=$ pure psychosocial).

- GP's familiarity with the patient $(1=$ bad, $5=$ good $)$.

\subsection{Inter-rater reliability}

The same person trained each group of (at least two) observers in each country in the same way with the aim of achieving equivalent ratings of the videotaped consultations in all countries. Observers were always native speakers. The inter-rater reliability (irr) was measured for each country separately by calculating Pearson's correlation coefficient for 20 consultations of different doctors rated by pairs of observers. It appeared that $79 \%$ of the irr's of the rated categories were quite good ( 0.7 or higher); $15 \%$ were moderately good (between 0.5 and 0.7 ) and $6 \%$ were too low $(<0.5)$ [29]. The low irr's mainly involved the cluster 
'other/unintelligible' (which was not included in the analyses) and the difference between 'information-giving' and 'counselling' (which categories were taken together in the analyses). The content validity and the discriminant validity of the RIAS proved to be satisfactory [35].

\subsection{Data analysis}

A $k$-means cluster analysis was used to identify homogeneous groups of consultations with similar communication patterns, using the SPSS/PC + program for hierarchic cluster analysis [36]. The communication variables (RIAS categories) of both GPs and patients were entered in the analysis reflecting the distinction between biomedical and psychosocial communication as well as the distinction between affective and instrumental communication. Nonverbal behaviour and consultation characteristics were also entered (see Table 4). At the first step of the cluster analysis all cases are considered separate clusters, at the second step two of the cases are combined into a single cluster, based on the criteria (RIAS categories, non-verbal behaviour and consultation characteristics). At every step, either individual case is added to clusters or already existing clusters are combined. So, each consultation was assigned to a single communication pattern.

Cluster analysis was chosen, firstly, to be able to give a broad typification of communicative behaviour during a consultation instead of a micro-analytical description of this behaviour. Secondly, in this way the emphasis was on the content (affective versus instrumental and biomedical versus psychosocial) rather than on the form (questionasking, information-giving, counselling) of the communication. Lastly, cluster analysis was preferred because of better manageability of three communication clusters instead of 16 categories. Differences on the communication patterns for the gender-dyads and nationalities, respectively, were analysed using the 'difference of proportions' test for independent (random) samples [37]. Analysis of variance (ANOVA) was used to contrast the communication patterns on four external variables (see Section 3.2) in order to investigate the validity of the cluster analysis.

For the second research question two-level multivariate (logistic) regression analyses were performed, which was necessary in order to account for the clustering of patients within GPs [39,40]. In other words, the doctor-patient communication of one doctor might tend to be more alike than those of other doctors, and they cannot a priori be considered as completely independent measurements. By using multilevel analysis the similarity among consultations by one GP was taken into account [41]. Using this method, data were analysed at the GP level, without disregarding the variance at the patient/consultation level (first level is the consultation, second level is the GP). The average intraclass correlation coefficients for GP and patient communication were 0.22 (range 0.08-0.39), which indeed warranted multilevel analyses. Further, the multilevel analyses were used for taking into account relevant independent (control) variables (see Section 2.5), when analysing the relationship between gender and nationality with communication patterns.

The dependent variables were the three communication patterns created by making three dummy variables for the original variable communication pattern. For each of these three dummy variables separate analyses were performed.

The first three multilevel analyses (Table 5) were used to investigate the independent relationship of gender-dyad and nationality, respectively, with the three communication clusters (dummy variables), controlling for the relevant independent variables. For the four gender-dyads and the six countries were four and six dummy variables created, respectively. The female/female dyad and The Netherlands, respectively, were used as reference groups in Table 5. (Irrespective of which gender-dyad or country would be used as a reference group, the significances of the differences keep unchanged.) When testing the differences between gender-dyads or nationalities, e.g. between the gender-dyads in the biomedical cluster, the biopsychosocial and psychosocial clusters are reference groups for the biomedical cluster. Therefore, the mutual dependency between the three clusters should be taken into account. A useful method to overcome this problem is the use of seemingly unrelated regression analysis (SUR). In this method, none of the dependent variables appears in the other equations. However, when in each equation, as in our model, the same explanatory variables are included, the results of SUR are the same as those of normal regression analysis. Therefore, we present the results of ordinary (logistic) regression analysis [42].

Secondly, multilevel analyses were done in order to investigate whether the relationship between gender-dyads and communication patterns differed per country (Table 6). Twenty-four new variables were constructed by multiplying the dummy variables of gender-dyad and nationality, so that the interactive effect of gender-dyad and nationality could be calculated. The Netherlands was taken as reference group. For each gender-dyad within each communication cluster (dummy variable) a separate multilevel analysis was performed (in total 12 analyses).

In order to compare all groups to each other (including the reference groups) differences between gender-dyads, nationalities and nationality per gender-dyad (Tables 5 and 6) were tested on significance by means of the 'chisquare test for joint contrasts' for multilevel models [38].

\section{Results}

\subsection{Sample characteristics}

Twice as many male than female GPs participated in the study, in total 190 GPs (Table 1). Only in Spain and The Netherlands were an equal number of male and female GPs 
included, due to the oversampling of women. Especially in the United Kingdom female doctors were reluctant to take part: only four female GPs participated.

The low participation of female GPs in four of the six countries led to the low occurrence of the gender-dyad female GP and male patient and also the female/female dyad was less common (Table 2). In all countries the male and female GPs were more often visited by female than by male patients, reflecting that the overall patient sample was more female than male. Two third of the consultations were with male GPs.

\subsection{Characteristics of communication patterns}

The cluster analysis revealed three well distinguishable patterns of communication between GPs and patients: a biomedical, a biopsychosocial and a psychosocial pattern (Table 3). A solution of four or five clusters could not be interpreted well. The patterns were based on percentages of key communication variables and consultation characteristics, and were expressed as percentages of the total of utterances of GPs and patients, respectively. In consultations with a psychosocial pattern, for example, $20 \%$ of GP's communication and $41.5 \%$ of patient's communication was about psychosocial topics.

The validity of the cluster analysis was investigated by means of the relationship between four external variables: the relevance patients attached before their consultation to discuss biomedical and psychosocial issues, respectively, and the patients' evaluation of the discussion about these issues after the consultation [31]. The psychosocial relevance and evaluation were higher when the consultation was defined as psychosocial compared to the other two clusters $(P \leq 0.05)$. The biomedical relevance was higher for the clusters biomedical and biopsychosocial than for the psychosocial cluster $(P \leq 0.05)$. Lastly, the biomedical oriented consultations differed from the biopsychosocial ones with respect to the relevance and evaluation of biomedical issues,

Table 3

Communication categories $(\%)^{\mathrm{a}}$, ratio of instrumental vs. affective talk and ratio of biomedical vs. psychosocial talk, per communication pattern

\begin{tabular}{|c|c|c|c|}
\hline & Biomedical & Biopsychosocial & Psychosocial \\
\hline \multicolumn{4}{|l|}{ GPs } \\
\hline \multicolumn{4}{|l|}{ Affective talk } \\
\hline Social talk & $5.83^{\mathrm{b}, \mathrm{c}}$ & $8.69^{\mathrm{d}}$ & $9.01^{\mathrm{d}}$ \\
\hline Agreement & $16.51^{\mathrm{b}, \mathrm{c}}$ & $11.59^{\mathrm{c}, \mathrm{d}}$ & $19.25^{\mathrm{b}, \mathrm{d}}$ \\
\hline Rapport building & $3.67^{\mathrm{c}}$ & $3.59^{\mathrm{c}}$ & $5.99^{\mathrm{b}, \mathrm{d}}$ \\
\hline Facilitation & 9.81 & 9.32 & 9.42 \\
\hline \multicolumn{4}{|l|}{ Instrumental talk } \\
\hline Procedural statements & $9.75^{\mathrm{b}, \mathrm{c}}$ & $12.69^{\mathrm{c}, \mathrm{d}}$ & $7.92^{\mathrm{b}, \mathrm{d}}$ \\
\hline Biomedical talk & $46.20^{\mathrm{b}, \mathrm{c}}$ & $42.58^{\mathrm{c}, \mathrm{d}}$ & $24.14^{\mathrm{b}, \mathrm{d}}$ \\
\hline Psychosocial talk & $5.44^{\mathrm{b}, \mathrm{c}}$ & $6.71^{\mathrm{c}, \mathrm{d}}$ & $20.03^{\mathrm{b}, \mathrm{d}}$ \\
\hline Ratio instrumental/affective & 1.7 & 1.9 & 1.2 \\
\hline Ratio biomedical/psychosocial & 8.5 & 6.4 & 1.2 \\
\hline \multicolumn{4}{|l|}{ Patients } \\
\hline \multicolumn{4}{|l|}{ Affective talk } \\
\hline Social talk & $6.89^{\mathrm{b}, \mathrm{c}}$ & $10.36^{\mathrm{d}}$ & $9.67^{\mathrm{d}}$ \\
\hline Agreement & $19.33^{\mathrm{c}}$ & $18.88^{\mathrm{c}}$ & $15.89^{\mathrm{b}, \mathrm{d}}$ \\
\hline Rapport building & 2.83 & 2.80 & 3.19 \\
\hline Facilitation & $2.85^{\mathrm{c}}$ & $3.10^{\mathrm{c}}$ & $2.36^{\mathrm{b}, \mathrm{d}}$ \\
\hline \multicolumn{4}{|l|}{ Instrumental talk } \\
\hline Biomedical talk & $52.29^{\mathrm{b}, \mathrm{c}}$ & $45.27^{\mathrm{c}, \mathrm{d}}$ & $21.66^{\mathrm{b}, \mathrm{d}}$ \\
\hline Psychosocial talk & $11.34^{\mathrm{c}}$ & $12.55^{\mathrm{c}}$ & $41.50^{\mathrm{b}, \mathrm{d}}$ \\
\hline Ratio instrumental/affective & 2.0 & 1.6 & 2.0 \\
\hline Ratio biomedical/psychosocial & 4.6 & 3.6 & 0.5 \\
\hline \multicolumn{4}{|l|}{ Consultation characteristics } \\
\hline Consultation length (min) & $10.16^{\mathrm{c}}$ & $9.73^{\mathrm{c}}$ & $12.36^{\mathrm{b}, \mathrm{d}}$ \\
\hline Eye contact $(\%)$ & $60.82^{\mathrm{b}, \mathrm{c}}$ & $26.31^{\mathrm{c}, \mathrm{d}}$ & $56.24^{\mathrm{b}, \mathrm{d}}$ \\
\hline Speaking time GP (\%) & $54.78^{\mathrm{b}, \mathrm{c}}$ & $56.48^{\mathrm{c}, \mathrm{d}}$ & $50.83^{\mathrm{b}, \mathrm{d}}$ \\
\hline Physical exam time (\%) & $14.73^{\mathrm{b}, \mathrm{c}}$ & $20.23^{\mathrm{c}, \mathrm{d}}$ & $8.31^{\mathrm{b}, \mathrm{d}}$ \\
\hline$N$ & 798 & 1229 & 673 \\
\hline
\end{tabular}

Values are significant at $P \leq 0.05$.

a Percentages do not add up to $100 \%$ because the category 'other/unintelligable' was excluded from the analyses.

${ }^{\mathrm{b}}$ Score differs significantly from score of the biopsychosocial cluster.

${ }^{\mathrm{c}}$ Score differs significantly from score of the psychosocial cluster.

${ }^{\mathrm{d}}$ Score differs significantly from score of the biomedical cluster. 
Table 4

Percentages of communication pattern by gender-dyad (GP/patient), total and by country

\begin{tabular}{|c|c|c|c|c|c|}
\hline & $\mathrm{M} / \mathrm{M}$ & $\mathrm{M} / \mathrm{F}$ & $\mathrm{F} / \mathrm{M}$ & $\mathrm{F} / \mathrm{F}$ & Total \\
\hline \multicolumn{6}{|l|}{ Biomedical } \\
\hline The Netherlands & 43.5 & 37.8 & 44.4 & 45.8 & 187 \\
\hline United Kingdom & 39.0 & 39.6 & 14.3 & 35.9 & 129 \\
\hline Spain & $13.6^{\mathrm{a}, \mathrm{b}}$ & $8.8^{\mathrm{a}, \mathrm{b}}$ & $27.1^{\mathrm{c}, \mathrm{d}}$ & $30.6^{\mathrm{c}, \mathrm{d}}$ & 92 \\
\hline Belgium & $10.7^{\mathrm{b}}$ & 12.7 & 14.3 & $20.0^{\mathrm{c}}$ & 60 \\
\hline Germany & 34.8 & 30.9 & 27.6 & 28.0 & 208 \\
\hline Switzerland & $37.9^{\mathrm{a}}$ & $31.8^{\mathrm{a}}$ & $8.3^{\mathrm{b}, \mathrm{c}, \mathrm{d}}$ & $37.3^{\mathrm{a}}$ & 122 \\
\hline Total & 30.3 & $27.3^{\mathrm{b}}$ & 27.7 & $33.5^{\mathrm{d}}$ & 798 \\
\hline \multicolumn{6}{|l|}{ Biopsychosocial } \\
\hline The Netherlands & 41.3 & 41.7 & 44.4 & 33.3 & 172 \\
\hline United Kingdom & 25.5 & 26.8 & 28.6 & 25.6 & 88 \\
\hline Spain & $71.2^{\mathrm{b}}$ & $68.8^{\mathrm{b}}$ & $60.0^{\mathrm{b}}$ & $43.4^{\mathrm{a}, \mathrm{c}, \mathrm{d}}$ & 251 \\
\hline Belgium & $72.2^{\mathrm{a}, \mathrm{b}}$ & $70.5^{\mathrm{a}, \mathrm{b}}$ & $50.0^{\mathrm{c}, \mathrm{d}}$ & $46.3^{\mathrm{c}, \mathrm{d}}$ & 295 \\
\hline Germany & 42.9 & 39.3 & 44.8 & 49.0 & 284 \\
\hline Switzerland & 38.7 & 35.8 & $50.0^{\mathrm{b}}$ & $29.9^{\mathrm{a}}$ & 139 \\
\hline Total & $47.4^{\mathrm{b}}$ & $46.3^{\mathrm{b}}$ & $49.4^{\mathrm{b}}$ & $39.6^{\mathrm{a}, \mathrm{c}, \mathrm{d}}$ & 1229 \\
\hline \multicolumn{6}{|l|}{ Psychosocial } \\
\hline The Netherlands & 15.2 & 20.5 & 11.1 & 20.8 & 79 \\
\hline United Kingdom & 35.5 & 33.6 & 57.1 & 38.5 & 119 \\
\hline Spain & 15.2 & 22.4 & $12.9^{\mathrm{b}}$ & $26.0^{\mathrm{a}}$ & 92 \\
\hline Belgium & $17.2^{\mathrm{a}, \mathrm{b}}$ & $16.8^{\mathrm{a}, \mathrm{b}}$ & $35.7^{\mathrm{c}, \mathrm{d}}$ & $33.8^{\mathrm{c}, \mathrm{d}}$ & 96 \\
\hline Germany & 22.3 & 29.8 & 27.6 & 23.0 & 173 \\
\hline Switzerland & $23.4^{\mathrm{a}}$ & 32.4 & $41.7^{\mathrm{c}}$ & 32.8 & 114 \\
\hline Total & $22.3^{\mathrm{b}, \mathrm{d}}$ & $26.4^{\mathrm{c}}$ & 22.9 & $26.9^{c}$ & 673 \\
\hline
\end{tabular}

Values are significant at $P \leq 0.05$.

${ }^{a}$ Score differs significantly from score of the female/male gender-dyad.

${ }^{\mathrm{b}}$ Score differs significantly from score of the female/female gender-dyad.

${ }^{\mathrm{c}}$ Score differs significantly from score of the male/male gender-dyad.

${ }^{\mathrm{d}}$ Score differs significantly from score of the male/female gender-dyad.

which was higher for the biomedical consultations $(P \leq 0.05)$. No difference was found with respect to the psychosocial issues. So, the cluster analysis revealing three clusters seemed to be valid.

A comparison of these patterns yielded the following characterisation.

\subsubsection{Biomedical pattern}

There is little social talk between GPs and patients and little rapport building, and an average number of procedural statements (ratio instrumental/affective talk GPs 1.7 and patients 2.0). Much talk is devoted to biomedical topics ( $46 \%$ by GPs, $52 \%$ by patients) and there is little psychosocial talk (ratio biomedical/psychosocial talk GPs 8.5 and patients 4.6). In this pattern, the consultation length is average (about $10 \mathrm{~min}$ ), and $15 \%$ of the consultation time is spent on physical examination. GPs often gaze in the patients' direction ( $61 \%$ of the possible time).

\subsubsection{Biopsychosocial pattern}

This pattern differs from the pure biomedical pattern in more exchange of social talk by both GPs and patients and less agreements made by the doctor. There are relatively more procedural statements by the GP and less biomedical talk by GPs as well as patients than in the former pattern (ratio instrumental/affective 1.9 and 1.6, respectively). There is somewhat more balance between biomedical and psychosocial talk, but the biomedical topics still dominate (ratio biomedical/psychosocial GPs 6.4 and patients 3.6). Relatively more time is devoted to physical examinations $(20 \%)$. Finally, the GPs look much less at their patients than in the other patterns $(26 \%)$.

\subsubsection{Psychosocial pattern}

In this pattern the level of GPs' rapport building is the highest and GPs more often agree by giving back-channels, whereas the level of procedural statements is the lowest (ratio instrumental/affective GPs 1.2 and patients 2.0). Psychosocial talk dominates the communication (ratio biomedical/psychosocial GPs 1.2 and patients 0.5 ), especially when the patients are speaking (twice as much psychosocial than biomedical talk by the patient). The patients have more speaking time (as much as the GPs). Finally, the consultations are the longest $(12.5 \mathrm{~min})$, there are few physical examinations and there is much eye contact.

The mixed biopsychosocial communication pattern was most common in general practices (45\% of the visits). The 
Table 5

Multilevel (logistic) regression analysis: regression coefficients $(\beta)$ of gender-dyads and nationalities with respect to the biomedical, biopsychosocial and psychosocial communication pattern $^{\mathrm{a}}$

\begin{tabular}{llcc}
\hline & Biomedical $\beta$ & Biopsychosocial $\beta$ & Psychosocial $\beta$ \\
\hline Gender-dyads & & & $0.39^{\mathrm{b}}$ \\
Male/male & -0.20 & $0.45^{\mathrm{b}}$ & $-0.36^{\mathrm{b}, \mathrm{c}}$ \\
Male/female & $-0.34^{\mathrm{b}}$ & 0.24 & -0.23 \\
Female/male & $-0.46^{\mathrm{b}}$ & Reference & Reference \\
Female/female & Reference & & \\
Nationalities & & Reference & $1.02^{\mathrm{d}}$ \\
The Netherlands & Reference & $-0.73^{\mathrm{e}, \mathrm{f}, \mathrm{g}, \mathrm{h}, \mathrm{i}}$ & 0.41 \\
United Kingdom & $-0.17^{\mathrm{e}, \mathrm{f}}$ & $0.91^{\mathrm{g}, \mathrm{h}, \mathrm{i}}$ & $0.44^{\mathrm{g}}$ \\
Spain & $-1.23^{\mathrm{g}, \mathrm{h}, \mathrm{I}}$ & $1.04^{\mathrm{g}, \mathrm{h}, \mathrm{i}}$ & $0.56^{\mathrm{g}}$ \\
Belgium & $-1.60^{\mathrm{g}, \mathrm{h}, \mathrm{I}}$ & $0.17^{\mathrm{e}, \mathrm{f}}$ & $0.55^{\mathrm{g}}$ \\
Germany & $-0.50^{\mathrm{g}, \mathrm{e}, \mathrm{f}}$ & $-0.13^{\mathrm{e}, \mathrm{f}}$ & \\
Switzerland & $-0.14^{\mathrm{e}, \mathrm{f}}$ & & \\
\hline
\end{tabular}

Values are significant at $P \leq 0.05$.

${ }^{\text {a }}$ Control variables included: patient's age, educational level, emotional feelings and health status; GP's age, diagnosis (psychosocial or not), assessment of psychosocial background of the patient's problems, familiarity with the patient.

${ }^{\mathrm{b}}$ Score differs significantly from score of female GP/female patient.

${ }^{c}$ Score differs significantly from score of female GP/male patient.

${ }^{\mathrm{d}}$ Score differs significantly from score of male GP/female patient.

${ }^{\mathrm{e}}$ Score differs significantly from score of country 3 (Spain).

${ }^{\mathrm{f}}$ Score differs significantly from score of country 4 (Belgium).

${ }^{\mathrm{h}}$ Score differs significantly from score of country 5 (Germany).

${ }^{\mathrm{g}}$ Score differs significantly from score of country 1 (The Netherlands).

${ }^{\mathrm{i}}$ Score differs significantly from score of country 6 (Switzerland).

biomedical and psychosocial patterns were found in 30 and $25 \%$ of the consultations, respectively.

\subsection{Differences in communication patterns between gender-dyads across countries}

Across the six countries the differences were mainly between the female/female dyad and the other dyads (see totals in Table 4). A biomedical pattern was more usual when female patients visited a female than a male GP (33.5\% versus $27.3 \%$ of the visits). Nearly $40 \%$ of the consultations of the female GPs with their female patients followed the biopsychosocial pattern that was less often than the consultations of the other gender-dyads. The psychosocial pattern was more common when female patients visited their (male or female) doctor, than when male patients consulted a male doctor (26.4 and 26.9\%, respectively, versus $22.3 \%$ of the consultations).

\subsection{Differences in communication patterns of gender-dyads between countries}

The differences found in the communication patterns across the six countries were not reflected in the separate countries (Table 4). Contrary to the other countries, no differences were found between the gender-dyads in The Netherlands, United Kingdom and Germany. Moreover, there were sometimes large differences in the occurrence of patterns between the countries, irrespective of differences between gender-dyads. Psychosocial patterns, for example were more usual in English than in Dutch consultations, and the biopsychosocial patterns more often occurred in Spain and Belgium than in Germany or Switzerland.

The differences between countries are also clear when looking at differences per country, as is shown from the following examples. In Spain the biomedical pattern occurred more often in the consultations of female than male GPs (irrespective of patients' gender), whereas in Belgium the biopsychosocial pattern differed between the same-gender-dyad consultations. In Switzerland, the biopsychosocial pattern more often occurred when female GPs talked with women than with men. In Spain this pattern was more usual in female/female visits than in the other ones. The Spanish female GPs and their female patients talked more often about psychosocial topics than when the patient was a man. In Belgium a psychosocial oriented consultation was more common when female as well as male patients visited a female GP.

\subsection{Influence of gender-dyads and nationalities on communication patterns}

In Tables 5 and 6 the results of the multilevel logistic analyses are shown by means of regression coefficients of gender-dyads (when controlling for nationality) and nationalities (when controlling for gender-dyad), with the three dummy variables for the communication patterns as the dependent variables (control variables as described in Section 2.7 were also included). 
Table 6

Multilevel (logisitc) regression analysis: regression coefficients $(\beta)$ of nationalities per gender-dyad with respect to the biomedical, biopsychosocial and psychosocial communication pattern ${ }^{\mathrm{a}}$

\begin{tabular}{|c|c|c|c|}
\hline & Biomedical $\beta$ & Biopsychosocial $\beta$ & Psychosocial $\beta$ \\
\hline \multicolumn{4}{|c|}{ Gender-dyad male/male } \\
\hline The Netherlands & Reference & Reference & Reference \\
\hline United Kingdom & $0.23^{\mathrm{b}, \mathrm{c}}$ & $-0.82^{\mathrm{b}, \mathrm{c}, \mathrm{d}}$ & $0.48^{\mathrm{c}, \mathrm{e}}$ \\
\hline Spain & $-1.00^{\mathrm{d}, \mathrm{e}, \mathrm{f}, \mathrm{g}}$ & $0.88^{\mathrm{d}, \mathrm{e}, \mathrm{f}, \mathrm{g}}$ & -0.24 \\
\hline Belgium & $-1.15^{\mathrm{d}, \mathrm{e}, \mathrm{f}, \mathrm{g}}$ & $0.99^{\mathrm{d}, \mathrm{e}, \mathrm{f}, \mathrm{g}}$ & $-0.30^{f}$ \\
\hline Germany & $0.23^{\mathrm{b}, \mathrm{c}}$ & $-0.16^{\mathrm{b}, \mathrm{c}}$ & -0.11 \\
\hline Switzerland & $0.55^{\mathrm{b}, \mathrm{c}, \mathrm{d}}$ & $-0.32^{\mathrm{b}, \mathrm{c}}$ & $-0.23^{\mathrm{f}}$ \\
\hline \multicolumn{4}{|c|}{ Gender-dyad male/female } \\
\hline The Netherlands & Reference & Reference & Reference \\
\hline United Kingdom & $0.38^{\mathrm{b}, \mathrm{c}}$ & $-0.96^{\mathrm{b}, \mathrm{c}, \mathrm{d}, \mathrm{g}}$ & $0.46^{\mathrm{c}}$ \\
\hline Spain & $-1.63^{\mathrm{d}, \mathrm{e}, \mathrm{f}, \mathrm{g}}$ & $1.10^{\mathrm{d}, \mathrm{e}, \mathrm{f}, \mathrm{g}}$ & -0.02 \\
\hline Belgium & $-1.07^{\mathrm{d}, \mathrm{e}, \mathrm{f}, \mathrm{g}}$ & $1.17^{\mathrm{d}, \mathrm{e}, \mathrm{f}, \mathrm{g}}$ & $-0.56^{\mathrm{d}, \mathrm{f}, \mathrm{g}}$ \\
\hline Germany & $-0.04^{\mathrm{b}, \mathrm{c}}$ & $-0.17^{\mathrm{b}, \mathrm{c}, \mathrm{f}}$ & $0.25^{\mathrm{c}}$ \\
\hline Switzerland & $0.33^{\mathrm{b}, \mathrm{c}}$ & $-0.30^{\mathrm{b}, \mathrm{c}}$ & 0.03 \\
\hline \multicolumn{4}{|c|}{ Gender-dyad female/male } \\
\hline The Netherlands & Reference & Reference & Reference \\
\hline United Kingdom & 0.17 & -0.65 & 0.35 \\
\hline Spain & -0.40 & 0.44 & $-0.22^{\mathrm{c}, \mathrm{e}}$ \\
\hline Belgium & -1.33 & 0.07 & $1.00^{\mathrm{b}, \mathrm{d}}$ \\
\hline Germany & -0.61 & 0.04 & 0.50 \\
\hline Switzerland & $-1.56^{\mathrm{d}}$ & 0.08 & $1.00^{\mathrm{b}, \mathrm{d}}$ \\
\hline \multicolumn{4}{|c|}{ Gender-dyad female/female } \\
\hline The Netherlands & Reference & Reference & Reference \\
\hline United Kingdom & 0.27 & -1.02 & 0.75 \\
\hline Spain & 0.06 & -0.11 & 0.18 \\
\hline Belgium & $-0.76^{\mathrm{e}}$ & -0.10 & $0.90^{\mathrm{d}, \mathrm{g}}$ \\
\hline Germany & -0.09 & $0.37^{\mathrm{e}}$ & $-0.35^{\mathrm{c}}$ \\
\hline Switzerland & $0.63^{\mathrm{d}}$ & $-0.68^{\mathrm{g}}$ & 0.10 \\
\hline
\end{tabular}

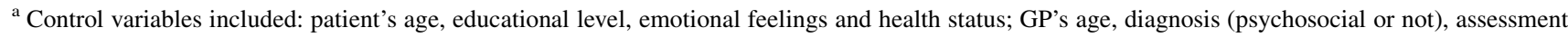
of psychosocial background of the patient's problems, familiarity with the patient.

${ }^{\mathrm{b}}$ Score differs significantly from score of country 3 (Spain).

${ }^{c}$ Score differs significantly from score of country 4 (Belgium).

${ }^{\mathrm{d}}$ Score differs significantly from score of country 1 (The Netherlands).

e Score differs significantly from score of country 6 (Switzerland).

${ }^{\mathrm{f}}$ Score differs significantly from score of country 2 (United Kingdom).

${ }^{\mathrm{g}}$ Score differs significantly from score of country 5 (Germany).

Differences between gender-dyads mainly concern the female/female dyad versus one or two of the other dyads. In consultations of female doctors and female patients the chance on a biomedical communication pattern is higher than in cross-gender consultations (a negative $\beta$ means that the chance is lower in relation to the reference group, i.e. The Netherlands). The biopsychosocial pattern will more often occur in consultations between (male and female) patients and male GPs than when female patients visit female GPs. The chance of a psychosocial oriented consultation is higher when the doctor is a woman (irrespective of the patient's gender) than in male/male consultations.

The likelihood of a specific communication pattern does differ between countries. In Spain and Belgium there is a lower chance of a biomedical communication pattern than in the other four countries. On contrast, the biopsychosocial pattern probably occurs more often in Spain and Belgium. In the United Kingdom the chance of a biopsychosocial pattern is the lowest compared to the other five countries. Lastly, consultations with much psychosocial talk occur less often in The Netherlands and more often in the United Kingdom than in the other four countries.

\subsection{Influence of gender-dyads per nationality on communication patterns}

Most differences between countries were found in the male/male and male/female dyad. In consultations of these two dyads, in Spain and Belgium the chance of a biomedical pattern is lower and the chance of a biopsychosocial pattern is higher than in the other countries. So, the finding in the former paragraph that the chance of these patterns is higher or lower, respectively, in these countries, can be attributed to the consultations of male GPs with their (male and female) patients. Differences between countries were not found in female GPs' consultations. The occurrence of the 
psychosocial pattern differed only between some countries. In Belgium, for example, consultations between females were likely to be more psychosocial oriented than in Germany and The Netherlands. In English male/male consultations the chance of a psychosocial pattern was lower in Germany and Switzerland than in the United Kingdom.

\section{Discussion}

\subsection{General conclusions}

The main results referring to the research questions are:

(1) Across countries, the psychosocial pattern is more common in consultations with female patients, which is in conformity with our expectations. The biopsychosocial pattern occurs less often in the female/female consultations than in the other gender-dyads. Contrary to expectations, the biomedical pattern is more common in female/female than in male/female consultations. Differences between countries concern both the extent to which the three patterns occur and the differences per country between the four gender-dyads.

(2) In the female/female dyad patterns differ from the other dyads. Differences between countries are mainly with respect to the biomedical and biopsychosocial pattern, in particular between Belgium and Spain on the one side, and the other four countries on the other side. These differences can especially be ascribed to differences in consultations of male doctors, irrespective of the patients' gender.

This study shows that it is important to take into consideration differences between countries when studying gender effects on communication across countries or when comparing studies performed in different countries.

\subsection{Communication patterns}

The three communication patterns reflect the distinction between biomedical and psychosocial talk and between affective and instrumental talk. Therefore, it is not surprising that the mixed pattern of biomedical and psychosocial is prevailing in nearly half of the consultations. The psychosocial pattern reflects the psychosocial dimension well, as was demonstrated by the high percentage of psychosocial talk of GPs and especially of patients. Moreover, the validation by external variables was satisfactory. The biomedical and biopsychosocial pattern were more alike, but the biopsychosocial pattern showed more social and psychosocial talk and physical exams occurred more frequently. Maybe this is an explanation for the much lower percentage of patient-directed gaze in this pattern than in the biomedical and psychosocial patterns ( $26 \%$ versus $61 \%$, respectively $56 \%$ ). Physical examinations may involve more procedural statements by the doctor (giving directions what to do) and more time to registration of examination results. Another explanation may be that in biomedical-type visits the patient gives a lot of information to the doctor while the doctor is listening to and looking at the patient. Anyhow, non-verbal behaviour such as eye contact is important for shaping a relationship with the patient and for making the patient feel known and understood [43]. It is, therefore, recommended to study this aspect further and to integrate it in medical education.

Roter [22] found in her study on communication patterns in primary care in the United States five distinctive communication patterns, four of which can be compared with the three patterns found in the present European study. Roter's narrow and expanded biomedical patterns form the biomedical pattern that resulted from this study. Her biopsychosocial and psychosocial patterns are similar to those found in the present study. However, the consumerist pattern was exclusively for the US study, and was characterised by the use of the doctor as a consultant who answers questions rather than one who asks them. Probably, the differences between the two studies arise from the different communication variables included in the cluster analysis, and from the inclusion of both GPs' and patients' communication. In the present study giving information and asking questions about biomedical or psychosocial topics were taken together as biomedical or psychosocial talk. Further, in the present study also consultation characteristics were included, such as patient-directed gaze - an important factor in communication - which might have contributed to different results from the cluster analysis.

Another explanation could be that 'consumerists' are typically American, because this pattern is most 'own to business', as Roter wrote, with little need for patient dialogue prompts or psychosocial exchange, but high patient question-asking and receptivity to physician information about biomedical topics. Maybe, in Western Europe patients are (not yet) used to see the doctor as a 'business (wo)man', but more as a family doctor who is not only visited for biomedical problems but also for psychological problems or family- and work-related problems.

\subsection{Differences in communication patterns of gender-dyads across countries}

The general conclusion is that communication patterns of gender-dyads differ across general practices in six WesternEuropean countries, but not much. The main differences are between the female/female gender-dyad and the other gender-dyads. Firstly, the biomedical pattern is more common in female/female than in male GP/female patient consultations, whereas the biopsychosocial pattern is seen less often. Probably, female doctors are focused at either biomedical or psychosocial issues, instead of a mixture of these issues.

Secondly, female patients talk easier about psychosocial topics, which becomes clear from the higher percentage of the psychosocial pattern in the dyads with female patients. However, the occurrence of these patterns was equal for male and female GPs, which is not in accordance with the 
literature showing that the female/female dyad is most psychosocially oriented. Maybe female patients take or get more time to tell their story to either a male or a female doctor, especially psychosocial oriented stories. This seems in accordance with the psychosocial pattern, which is characterised by longer consultations, more speaking time for the patient and more back-channels and agreements by the doctor, implying that the doctors listen well to the patients.

However, the psychosocial pattern occurs less often when a male patient visits a female doctor. Possibly, female doctors and male patients still have to get used to each other, because only in the last decade has the number of female doctors been rising, at least in Western Europe. There was no obligation for men to choose a female doctor, and therefore, they have chosen a male doctor for the greater part. With the expectation that this dyad will become more common in the future, it will be interesting to investigate the possible change of the female $\mathrm{GP} /$ male patient dyad into a psychosocial communication pattern in the future.

Hopefully, the ongoing second Eurocommunication study will answer this question sooner, because in the EasternEuropean countries involved in that study there are more female than male doctors. In Estonia, for instance, $95 \%$ of the doctors are women; so Estonian patients are used to women doctors. Therefore, the results of that study may be important for Western-European health policy, among others because psychosocial oriented consultations are longer than other ones.

\subsection{Influence of gender-dyads and nationalities on communication patterns}

Doctor and patient gender influence the chance of a psychosocial communication pattern, especially if female GPs talk with female patients. In view of the still growing number of people with psychosocial problems and because more women than men visit the GP for psychosocial problems, in all (Western-European) countries, health policymakers should be aware that they will claim much time and much effort from general practitioners. This applies especially to countries where the GP has the gatekeeper role, which means that the GP is often the first doctor to contact for health problems and to detect and treat these problems, at least initially.

The influence on communication patterns of genderdyads per country shows that different cultural norms and values prevailing in countries may be related to the communicative behaviour of doctors and patients apart from their gender. However, this influence could be mainly attributed to different communication patterns in male GPs' consultations, which may traditionally be embedded more firmly within the specific cultural setting.

\subsection{Conclusions}

This study shows that it is important to take into consideration differences within countries when studying gender effects on communication across countries or when comparing studies performed in different countries.

More detailed studies are needed into the influence of cultural characteristics, apart from gender influence, as expressed in norms and values with respect to health and health behaviour. In some cultures, for instance, men dominate women more or the medical professional has a higher status than in other cultures, which may influence doctorpatient communication. Also within countries differences may exist, as in Belgium and Switzerland with a division of the population based on two different languages and probably different norms and values.

\subsection{Practice implications}

In view of the ongoing feminization of medical care, national healthcare policymakers and healthcare educators should be aware of the consequences of the shift from mainly male GP consultations to more or at least an equal percentage of female GP consultations. Especially the female $\mathrm{GP} /$ male patient gender-dyad is expected to increase in the future, which may ask for adequate policy measures.

At the international level, within the European Union, differences in communication patterns between countries should be taken into consideration, because the ongoing European harmonisation is leading to the integration of healthcare and healthcare policies [44]. Recently, for instance, several Belgian GPs have left their own country and started a practice in The Netherlands, because in Belgium there is a surplus of GPs and the working circumstances are worse than in The Netherlands. In addition, German doctors are inviting Dutch patients to visit a German doctor. It is expected that this exchange of medical professionals and patients will increase. So, it will be necessary to include gender-specific as well as cross-cultural communication training into (post-graduate) education.

\section{Acknowledgements}

The study has been made possible by funding from the BIOMED-II research programme of the European Union (contract no. BMH4-CT96-1515). The authors wish to thank the national coordinators/contractors/researchers of the participating countries of the Eurocommunication Study: P.F.M. Verhaak, J.M. Bensing, O. Bahrs, M. Deveugele, L. Gask, N. Mead, F. Leiva-Fernandez, A. Perez, P.D. Bösch, L. Oppizzi, M. Peltenburg.

\section{References}

[1] Roter DL, Hall JA. How physician gender shapes the communication and evaluation of medical care. Mayo Clin Proc 2001;76:673-6.

[2] Hall JA, Irish JT, Roter DL, Ehrlich CM, Miller LH. Gender in medical encounters: an analysis of physician and patient communication in a primary care setting. Health Psychol 1994;13:384-92. 
[3] Hall JA, Irish JT, Roter DL, Ehrlich CM, Miller LH. Satisfaction, gender, and communication in medical visits. Med Care 1994;32: 1216-31.

[4] Weisman CS, Teitelbaum MA. Physician gender and the physicianpatient relationship: recent evidence and relevant questions. Soc Sci Med 1985;20:1119-27.

[5] Bensing J, Brink-Muinen Avd, de Bakker D. Gender differences in practice style: a Dutch study of general practitioners. Med Care 1993; 31(3):219-29.

[6] Brink-Muinen Avd. Women's health care: for whom and why. Soc Sci Med 1996;44:1541-51.

[7] Lorber J. What impact have women physicians had on women's health? JAMA 2000;55(1):13-5.

[8] Roter DL, Hall JA. Why pshysician gender matters in shaping the psysician-patient relationship. J Women's Health 1998;7: 1093-7.

[9] Meeuwesen L, Schaap C, Staak Cv. Verbal analysis of doctor-patient communication. Soc Sci Med 1991;32:1143-50.

[10] Lunn R, Williams S, James R, Weinman J, Newman SP. The effects of gender upon doctor-patient interaction. Psychol Health 1998; 13:975-86.

[11] Skelton JR, Hobbs FDR. Descriptive study of cooperative language in primary care consultations by male and female doctors. BMJ 1999;318:576-9.

[12] Brink-Muinen Avd, Bakker DH, Bensing JM. Consultations for women's health problems: factors influencing women's choice of sex of general practitioner. Br J Gen Pract 1994;44:205-10.

[13] Hall JA. How big are nonverbal sex differences? The case of smiling and sensitivity to nonverbal cues. In: Canary DJ, Dindia K, editors. Sex Differences and Similarities in Communication: Critical Essays and Empirical Investigations of Sex and Gender in Interaction. Mahwah, NJ: Erlbaum, 1999. p. 155-77.

[14] Elderkin-Thompson V, Waitzkin H. Differences in clinical communication by gender. J Gen Intern Med 1999;14:112-21.

[15] Brink-Muinen Avd, Bensing JM, Kerssens JJ. Gender and communication style in general practice: differences between women's health care and regular health care. Med Care 1998; 36:100-6.

[16] Stewart M. Patient characteristics which are related to the doctorpatient interaction. Fam Pract 1983;1:30-6.

[17] Roter D, Lipkin S, Korsgaard A. Sex differences in patients' and physicians' communication during primary care visits. Med Care 1991;29:1083-93.

[18] Hall JA, Epstein AM, De Ciantis MC, McNeil BJ. Physicians' liking for their patients: more evidence for the role of affect in medical care. Health Psychol 1993;12:140-6.

[19] Martin CS, Arnold RM, Parker RM. Gender and medical socialization. J Health Soc Behav 1988;29:333-43.

[20] Weisman CS, Teitelbaum MA. Women and health care communication. Pat Educ Couns 1989;13:183-99.

[21] Dugardyn R. Communicatie tussen mannelijke arts en vrouwelijke patiënt gaat vaak mis [communication between male physician and female patient often goes wrong]. TSG 1994;11:14-6.

[22] Roter DL, Stewart M, Putnam SM, Lipkin M, Stiles W, Inui TS. Communication patterns of primary care physicians. JAMA 1997; 277:350-6.

[23] Bensing JM. Doctor-Patient Communication and the Quality of Care:
An Observation Study into Affective and Instrumental Behaviour in General Practice. Utrecht, NIVEL, 1991.

[24] Penn NE, Kar S, Kramer J, Skinner J, Zambrana RE. Ethnic minorities, health care systems and behavior. Health Psychol 1995; 14:641-6.

[25] Wieringen JC van, Harmsen JA, Bruijnzeels MA. Intercultural communication in general practice. Eur J Public Health 2002;1:63-8.

[26] Harmsen J, Meeuwesen L, Wieringen J van, Bernsen, Bruijnzeels M. When cultures meet in general practice, Patient Educ Couns 2003;in press.

[27] Cooper H, Smaje C, Arber S. Use of health services by children and young people according to ethnicity and social class: secondary analysis of a national survey. BMJ 1998;317:1047-51.

[28] Kleinman A. Patients and healers in the context of culture. Berkeley: Universiry of California Press, 1980.

[29] Brink-Muinen Avd, Verhaak PFM, Bensing JM, Bahrs O, Deveugele M, Gask L, Mead N, Leiva-Fernandes F, Perez A, Messerli V, Oppizzi L, Peltenburg M. The Eurocommunication Study: an International Comparative Study in Six European Countries on Doctor-Patient Communication in General Practice. Utrecht: NIVEL, 1999.

[30] Brink-Muinen Avd, Verhaak PFM, Bensing JM, et al. Doctor-patient communication in different European health care systems: relevance and performance from the patients' perspective, Pat Educ Couns 2000;39:115-27.

[31] Boerma WGW, Brink-Muinen Avd. Gender-related differences in the organization and provision of services among general practitioners in Europe: a signal to healthcare planners. Med Care 2000;10:993-1002.

[32] Lamberts H, Wood M, editors. International classification of primary care. Oxford: Oxford University Press, 1987.

[33] Roter DL. The Roter method of interaction process analysis. Baltimore: Johns Hopkins University, 1989.

[34] Weel C van, Konig-Zahn C, Touw-Otten FWMM, Duijn van NP, Meyboom-De Jong B. Measuring functional health status with the COOP/WONCA Charts: a manual. WONCA, ERGHO, $\mathrm{NCH}$, Groningen University, The Netherlands, 1995.

[35] Ong LML, Visser MRM, Kruyver IPM, Bensing JM, Brink-Muinen Avd, Stouthard JML, Lammes FB, Haes JCJM. The Roter Interaction Analysis System (RIAS) in oncological consultations: psychometric properties. Psycho-oncology 1998;7:387-401.

[36] SPSS Inc., Chicago, IL, USA.

[37] Blalock HM. Social statistics. Tokyo, Japan: McGraw-Hill, 1979.

[38] MlwiN. Multilevel models project, University of London, United Kingdom, 2000.

[39] Bryk AS, Raudenbusch SW. Hierarchical linear models: application and data analyses methods. Sage: Newbury Park, 1992.

[40] Goldstein H. Multilevel statistical models. 2nd ed. New York: Halsted Press, 1995.

[41] Rasbach J, Woodhouse G. Mln command reference. London, England: Institute of Education, University of London, 1995.

[42] Kroneman M. Healthcare systems and hospital bed use. Utrecht, NIVEL, 2001.

[43] Bensing JM, Kerssens JJ, Pasch Mv. Patient-directed gaze as a tool for discovering and handling psychosocial problems in general practice. J Nonverbal Behav 1995;19:223-42.

[44] Maynard M. Towards an integrated health care policy in the European Union? Eurohealth 1999;5:5-7. 